\title{
Bidirectional Associations Among Sensitive Parenting, Language Development, and Social Competence
}

\author{
Melissa A. Barnett ${ }^{\mathrm{a},{ }^{*}, \text { Hanna Gustafsson }}{ }^{\mathrm{b}}$, Min Deng ${ }^{\mathrm{c}}$, W. Roger Mills-Koonce ${ }^{\mathrm{d}}$, and Martha \\ Cox ${ }^{b}$ \\ aFamily Studies and Human Development, University of Arizona, Tucson, AZ, USA \\ ${ }^{b}$ Department of Psychology, University of North Carolina, Chapel Hill, NC, USA \\ c3-C Institute for Social Development, Cary, NC, USA \\ ${ }^{d}$ Center for Developmental Science, University of North Carolina, Chapel Hill, NC, USA
}

\section{Abstract}

Rapid changes in language skills and social competence, both of which are linked to sensitive parenting, characterize early childhood. The present study examines bidirectional associations among mothers' sensitive parenting and children's language skills and social competence from 24 to 36 months in a community sample of 174 families. In addition, this study examines how these developmental pathways vary by child sex. Findings indicate stability across time in sensitive parenting, expressive language skills, and social competence, as well as positive main effects of sensitive parenting on expressive and receptive language skills for girls and boys. We find mixed evidence over time of reciprocal links between social competence and sensitive parenting. Further, boys' receptive language skills at 24 months uniquely contribute to increases in mothers' observed sensitive parenting from 24 to 36 months. These findings highlight the utility of applying transactional frameworks to the study of sex-based differences in early developmental processes.

\section{Keywords}

parenting; social competence; language development; sex differences; early childhood

\begin{abstract}
Early childhood is a pivotal period for the development of social and cognitive skills. Language and social competence undergo significant, inter-related changes during the third year of life as children develop skills that become integrated and reciprocal. Sensitive parenting fosters development in each of these domains (e.g. Landry, Smith, Swank \& Miller-Loncar, 2000; Lengua, Honorado \& Bush, 2007). Transactional models of parenting and child development (e.g. Fischer \& Bidell, 2006; Sameroff, 2009) suggest that the associations are bidirectional such that mothers and children respond to each other's cues, and thus, a significant factor influencing parenting is children's behaviour. More specifically, receptive and expressive language skills and socially competent behaviours
\end{abstract}


may facilitate and be facilitated by sensitive parenting behaviours. Given sex differences in early development including faster language development for girls (e.g. Bornstein, Hahn \& Haynes, 2004; Galsworthy, Dionne, Dale \& Plomin, 2000) and better social competence among girls by school entry (e.g. Dunsmore, Noguchi, Garner, Casey \& Bhullar, 2008), the linkages among these domains of development and parenting may vary by child sex. The present study seeks to examine reciprocities between expressive and receptive language skills and social competence as well as between mothers' sensitive parenting and these domains of development from 24 to 36 months. The secondary goal is to explore how these reciprocal processes may vary by child sex.

Dynamic systems approaches to child development account for the complexity of development as it occurs across multiple domains and contexts. This perspective suggests that development occurs as a result of interacting systems that are internal (e.g. language and social skills) and external (e.g. parenting and language, parenting and social skills) to the developing child (Lerner, 2006; Thelen \& Smith, 2006). Development in each domain depends on development in other domains as children gain competence through engaging in specific activities in specific contexts. Although much of the work applying this perspective to child development has focused on motor or cognitive skills (e.g. Thelen \& Smith, 2006), researchers are increasingly using dynamic systems theory to describe the integration of individual children's developmental skills across varying domains as a result of increasingly complex interactions with the physical and social environment (Ayoub, Vallotton \& Mastergeorge, 2011; Fischer \& Bidell, 2006). We consider this approach as a framework for understanding interactions among language and social skills during toddlerhood.

In the next sections, we first discuss the development of language and social competence as distinct domains. We then consider interactive processes to link the development of language skills and social competence during early childhood, with a particular focus on variations by child sex. Next, we discuss transactional models of parent-child interactions characterized by sensitive parenting and language and social development. Finally, we consider the extent to which these dynamic interactions may vary according to child sex.

\section{Expressive and Receptive Language Development for Two-Year-Olds}

Two-year-olds experience rapid advances in language skills. The present study focuses on two related aspects of language development. Expressive language is the extent to which children are able to use words and non-verbal gestures to communicate effectively with others. Receptive language is the extent to which children are able to understand words and non-verbal language cues presented by others. Both expressive and receptive language skills often emerge in social contexts, such as parent-child interactions. The best predictor of children's language ability at any given assessment point during early childhood is language ability at the previous assessment point (e.g. Bornstein et al., 2004). However, it is important to identify other processes that may disrupt or facilitate stability in language development due to long-term implications for children's cognitive development.

Young children experience increasing social competence as their ability to attend to, interpret, and predict social partners' behaviours increases, and self-regulation capacities 
improve (e.g. Baillargeon et al., 2007; Kochanska, Coy \& Murray, 2001). Social competence consists of the social skills necessary to engage in and sustain positive reciprocal relations with peers and teachers (e.g. Howes \& Phillipsen, 1998). Specific skills considered in the present study include cooperation, compliance, sharing, and turn-taking. These skills contribute to later social development and peer relationships (Howes \& Phillipsen, 1998). Thus, similar to expressive and receptive language skills, early social competence may impact later development.

\section{Reciprocities Among Language Development and Social Competence}

Although there is general acknowledgement that the development of language and social competence interact, there has been limited application of a dynamic systems approach to understand the nature of the processes linking language and social development during toddlerhood. Language is a social tool that develops through interactions with others, and the ability to use language provides opportunities to gain social skills. As children develop, social competence is increasingly tied to the ability to use language effectively to communicate needs and desires and to negotiate tasks such as sharing toys (Hay et al., 1999). Both receptive and expressive language skills are needed to engage in positive, reciprocal interactions, as children must understand and respond appropriately to the requests and comments of others. On the one hand, language ability may facilitate social competence (e.g. Horwitz et al., 2003; McCabe \& Meller, 2004). That is, children with language deficits may struggle to communicate and understand intentions and feelings of themselves and others, thus limiting their ability to verbally negotiate conflicts to reach prosocial solutions (Dionne et al., 2003; McCabe \& Meller, 2004). Over time, limited language abilities may lead to fewer social interactions and opportunities to gain social competence. In support of this perspective, Ayoub et al. (2011) report that 24-month expressive language positively predicted trajectories of self-regulation from 24 to 36 months. Alternatively, social competence may facilitate language development because socially competent children have more opportunities to participate in language-based exchanges (e.g. Gallagher, 1999). Likewise, poor social competence may limit social interactions and opportunities to practice and improve language skills, in turn leading to less optimal language and social competence development.

In addition to the direction of effects, the timing of the associations between social competence and language development is unclear. Several studies have noted links between language development and social skills as early as toddlerhood and continuing into preschool and kindergarten (e.g. Kaiser et al., 2000; Longoria et al., 2009; Rescorla et al., 2007). For example, Horwitz et al. (2003) demonstrated that among a community sample of almost 1200 children aged 18-29 months, language delay was associated with social competence. These findings suggest that as early as 18 months those children with language delays may be at risk for reduced social competence, or vice versa, those children with social competence deficits may be at risk for language delays. Identifying the specific pathways facilitating this association between language and social behaviours across early childhood would inform the development of prevention and intervention efforts by identifying children particularly at risk for later social and/or language problems. 


\section{Sex Differences in Pathways Linking Language Development and Social Competence}

Understanding developmental pathways linking language development and social competence may require considering child sex. Numerous studies have focused on meanlevel sex differences in language development and, to a lesser extent, in social competence. On average, starting during the second year of life, girls' expressive and receptive language development is slightly faster than boys' development (e.g. Ayoub et al., 2011; Bornstein et al., 2004; Dionne et al., 2003; Galsworthy et al., 2000). Although biology partially explains these sex differences, social and cultural influences are also important influences (Gleason \& Ely, 2002). In this regard, children's language development may be closely linked to social competence. Sex-based differences favouring girls' social competence generally emerge during the later preschool or early school years (e.g. Baillargeon et al., 2007; Dunsmore et al., 2008; Hay et al., 1999). However, the processes influencing the development and consequences of social competence may vary by sex (Dunsmore et al., 2008). Early female advantages in language development may in part influence later advantages in social competence.

A dynamic systems approach suggests that if language and social development undergird each other during toddlerhood, and if girls and boys are developing skills in these domains at different rates, then naturally the pathways linking these domains, and in turn influencing future development, would likely vary by child sex. For example, if limited language skills inhibit opportunities for social interactions that build social competence and better language skills, then if boys have more limited language skills than girls, these limitations may lead to less social competence over time as the cumulative effect of poorer language skills is linked to fewer opportunities for prosocial interactions. Studies of preschool and kindergarten children indicate that the links between language development and social competence are stronger for boys than for girls (Bouchard et al., 2008; Stowe, Arnold \& Ortiz, 1999). For example, Kaiser et al. (2000) demonstrated that boys who had low scores on standardized language assessments were $9 \%$ more likely than girls to have low parent-rated social skills. These findings suggest that by preschool, language and social skills are more strongly associated for boys. However, it remains unknown if this sex-based pattern emerges earlier in development. A goal of the present study is to examine potential sex differences in the relationship between language and social competence across the third year of life. This examination should include parenting behaviours because parent-child interactions are a significant context influencing language and social development for girls and boys.

\section{Sensitive Parenting, Language Development, and Social Competence}

Parenting that is supportive and sensitive is consistently positively associated with children's language and social competence development across early childhood (e.g. Lengua et al., 2007; Pungello et al., 2009; Tamis-LeMonda et al., 2001). For example, Pungello et al. (2009), using a subset of families included in the present study, found that when mothers were observed to be more sensitive at 12 and 24 months, their children experienced faster rates of development of expressive and receptive language from 18 to 36 months. These positive parenting behaviours may model language use, label the environment through joint 
attention, encourage and reinforce children's attempts to use language, and generally create a comfortable and interactive environment in which children have the freedom to experiment with language (Fenson et al., 1994; Tamis-LeMonda et al., 2001; Gleason \& Ely, 2002). Sensitive parenting also promotes the acquisition of social competence by fostering the development of self-regulation, and modelling and encouraging prosocial behaviours (e.g. Lengua, Honorado \& Bush, 2007; Spinrad et al., 2007). For example, Spinrad et al. (2007) reported that observed maternal support predicted increases in social competence from 18 to 30 months. The implicit assumption of this work on language development and social competence, however, is that parenting drives children's language development.

Transactional models of parent-child relationships characterize parent and child behaviours as interactive over time so that parents and children influence each other (Bornstein, 2009; Sameroff, 2009). These models suggest that parents are likely to interact differently with individual children as they respond to that child's specific characteristics, including sex, language ability, and social behaviours. Moreover, individual children may interpret parents' behaviours differently and thus display unique behaviours that in turn elicit unique parental responses (Bornstein, 2009). Child effects on parenting behaviours may be strongest during periods of marked developmental transitions, such as toddlerhood (Gross, Shaw \& Moilanen, 2008).

There is some support for transactional models of parenting and children's language development. Mothers may be more sensitive and positive towards children who themselves are sensitive and engaged. In turn, those children with more advanced language and social skills may be more sensitive to their mothers, encouraging escalated sensitivity. Bornstein $e t$ al. (2007) reported that 20-month-old children with larger expressive vocabularies were more sensitive to their mothers during parent-child interactions, and these children's mothers were rated as more sensitive than the mothers of children with smaller expressive vocabularies. Moreover, mothers were more sensitive as their children's expressive vocabularies increased over time. Similarly, Rowe (2000) reported that mothers of infants who perceived that their children could understand more language (i.e. had better receptive language) used more verbal and non-verbal communication with their children. The present study tests these bidirectional associations from 24 to 36 months to determine if children who have more advanced expressive and receptive language skills at 24 months elicit more sensitive parenting at 36 months, controlling for positive parenting at 24 months.

Transactional models have rarely been applied explicitly to the development of social competence. However, it seems likely that although positive parenting encourages the development of social competence, mothers with children who are more socially competent display more positive parenting because these children in general are easy to get along with and cooperative. Children's antisocial behaviours develop in the context of coercive parentchild reciprocal interactions such that parents' harsh responses to children's difficult behaviours lead to escalated difficult behaviours that in turn elicit harsher parenting (e.g. Patterson, 2002). Most transactional models of parent-child relationships focus on negative child outcomes and parenting behaviours (Gross et al., 2008), but similar processes, that likely underlie the development of positive behaviours. 


\section{Child Sex as a Moderator of Parent-Child Transactions}

Expressive and receptive language skills and social competence are two child characteristics that may influence mothers' parenting behaviours. Sex is another salient child characteristic likely to influence parenting. Reviewing the literature on child sex differences in parenting is beyond the scope of the present study. See Leaper (2002) for a review of this topic. Instead, we focus on the extent to which bidirectional associations between parenting and language skills, and parenting and social skills may vary by child sex. General approaches to behavioural sex differences during childhood assume a differential exposure or differential susceptibility model (Rutter, Caspi \& Moffitt, 2003). If girls and boys experience different exposure to mothers' sensitive parenting, then this difference may account for sex-based variation in language and social development. Alternatively, if boys and girls are exposed to similar levels of sensitive parenting, then sex differences in these skills may result in part from differential effects of sensitive parenting on the development of girls and boys. Importantly, mothers are both fostering and responding to the language and social cues of their children such that gender differences in language and social competence may be reinforced by patterns of mother-child interaction. The present study tests the extent to which children's language and social skills differentially influence and are influenced by sensitive parenting for girls and boys.

Some research indicates that the role of language may differ in mother-daughter and mother-son interactions. For example, in a meta-analysis of gender differences in parenting, Leaper, Anderson and Sanders (1998) noted that in general, mothers talk more during interactions, especially unstructured interactions, with their daughters than their sons. One interpretation of these findings suggests that girls have more advanced language skills because they have greater exposure to language in interactions with their mothers. However, a transactional perspective suggests that mothers may talk more to their daughters because their daughters use and comprehend more language. This interaction of maternal and daughter characteristics may in fact exaggerate gender differences in parent-child communication patterns (Leaper, 2002). The extent to which child gender influences reciprocal associations between sensitive parenting and social competence remains largely unexplored. Drawing from research on sex differences in the influences of parenting on behaviour problems, Calkins (2002) found that observed harsh parenting by mothers of 24month-olds was associated positively with emotional distress for boys only. This finding suggests that gender may moderate associations between sensitive parenting and social competence

\section{The Present Study}

The present study examines associations among parenting, language development, and social competence across the third year of life. Two primary hypotheses and a third hypothesis regarding sex differences were tested. Analyses control for 12-month observed parenting.

1. Language development and social competence are inter-related from 24 to 36 months such that development in each domain (e.g. expressive and receptive 
language skills) at a given time point would be associated positively with a score in the other domain (e.g. social competence) at the following time point, net the influence of within domain stability over time.

2. Mothers' sensitive parenting and development in each domain over time are interrelated in a cross-lag fashion. Specifically, we expect that 24-month social competence and expressive and receptive language are positively associated with 36-month sensitive parenting, controlling for 24-month sensitive parenting. Likewise, we hypothesized that 24-month sensitive parenting is positively associated with 36-month receptive and expressive language and social competence, net the influence of within domain stability over time.

3. These processes are expected to vary for girls and boys such that language development at one time point will be a stronger predictor of subsequent social competence among boys only. Given the exploratory approach to the role of gender as a moderator in parent-child transactions, we did not form specific hypotheses.

\section{METHOD}

\section{Participants}

Participants were drawn from the Durham Child Health and Development Study, a longitudinal study of child development in a socioeconomically and ethnically diverse sample living in and around a mid-sized southeastern city. Families were recruited within the first 3 months of the child's birth through phone contact via birth record searches and through fliers and advertisements. Of the 206 families participating in the initial 3-month assessment, 174 families were included in the present analyses. The present sample was 56\% $(n=101)$ European American and 44\% $(n=80)$ African American. ${ }^{1}$ Approximately $52 \%(n=90)$ of the children were girls. Mothers averaged $14.64(S D=2.49)$ years of education. The mean income-to-needs ratio assessed when the child was 12, 24, 30, and 36 months was $3.03(S D=2.30)$, ranging from .04 to 13.89. Income-to-needs ratios above 1.0 indicate that a family is able to provide for basic needs.

\section{Procedure}

Data were collected during laboratory visits when children were 12, 24, and 36 months of age. During the 12-month visit, mothers and children participated in a 10-min filmed freeplay interaction with a standardized set of toys. Parents were instructed to play with the children however they normally would if they had a few free minutes during the day. At the 24 and 36 month visits mothers and children were filmed during a 10-min puzzle completion task. The mother and child sat at a table. The mother was told that the child should complete the puzzle but that she could give any help she deemed necessary. Each time the dyad completed a puzzle, a more challenging puzzle was introduced, with a maximum of three

\footnotetext{
${ }^{1}$ We conducted post-hoc analyses examining potential ethnic differences in the reported findings. First, we re-estimated the models described in the Results section with a two group model (European American and African American) that also controlled for household income on 36-month variables, and we found no evidence that the patterns of associations varied by ethnicity. Second, we split the sample by ethnicity and estimated the two group (boys and girls) path models for expressive and receptive communication. Again, we failed to find evidence of significant variations in hypothesized associations by ethnicity. Detailed results are available by request from the first author.
} 
puzzles. During the 24- and 36-month lab visits, trained researchers administered the language assessment, and mothers completed several questionnaires, including an assessment of the child's social competence.

\section{Measures}

Parenting behaviour-Global observational ratings of parent behaviour at each time point were made on seven global rating scales revised from scales developed in the NICHD Study of Early Child Care (NICHD Early Child Care Research Network, 1999): sensitivity, intrusiveness, detachment/disengagement, positive regard for the child, negative regard for the child, animation, and stimulation of cognitive development. For the 12-month free-play tasks, maternal behaviour was rated using 5-point global rating scales (Cox \& Crnic, 2002). For the 24-month puzzle task, maternal behaviour was rated using 7-point global scales (Cox, 1997), and scores were converted to 5-point scales to attain metric consistency across time. Although the coding systems at the earlier and later time points were slightly different, the parenting behaviours included in the present analysis were identical across time points. At each wave, trained reliable coders, who were blind to other information about the families, scored the interactions for maternal behaviour. Two lead graduate student coders trained all other coders until acceptable reliability $(I C C>0.80)$ was maintained for each coder on every scale. At 12 months, all interactions were coded by two coders. Each coding pair met to reconcile scoring discrepancies, reaching a final consensus score for each scale. At 24 and 36 months, two highly experienced coders double-coded $30 \%$ of randomly selected cases and reached consensus scores. Inter-rater reliability on the double-coded cases was monitored continuously.

An exploratory factor analysis of maternal behaviour followed by an oblique (promax) rotation was conducted to inform the reduction of the number of variables analysed and to characterize maternal behaviour parsimoniously. This factor analysis suggested the existence of two distinct, relatively independent composites. Sensitive Parenting consisted of the mean of sensitivity/sensitiveness, the reverse score for detachment/disengagement, positive regard, stimulation of cognitive development, and animation, with high scores reflecting parenting behaviours that are sensitive, warm, child-centred, stimulating, and involved. Only the Sensitive Parenting composite was used in the present analyses. Intercoder reliabilities (ICC) for this composite were 0.88 at 12 months, 0.93 at 24 months, and 0.87 at 36 months.

Child social competence-Mothers completed the Adaptive Social Behaviours Inventory (ASBI; Hogan, Scott \& Bauer, 1992) when children were 24 and 36 months of age. This measure of social competence requires parents to rate the frequency of 30 behaviours on a 3 -point scale $(1=$ rarely or never, $2=$ sometimes, $3=$ almost always $)$. The ASBI consists of three subscales, two of which assess prosocial behaviours (express and comply) and one of which assesses normative/negative behaviours (disrupt). Only the prosocial scales were used in the present analyses. This instrument has demonstrated acceptable levels of validity and reliability (e.g. Cronbach's alpha $=.79$ for express and comply) in diverse samples of male and female preschoolers. The express subscale (Cronbach's alpha $=.80$ at each time point) consists of the mean of 13-items, including, 
'Understands others' feelings, like when they are happy, sad or mad', and 'Will join a group of children playing'. The comply subscale (Cronbach's alpha $=.78$, at 24 months, and .80 at 36 months) consists of the mean of 10 items, including, 'Is helpful to other children' and 'Follows rules in games'. These subscales were highly correlated at each time point $(r=.46$ to $.53, p<.001)$; thus, social competence at each time point was calculated as the mean of the express and comply subscales.

Child language-During the 24- and 36-month assessments, trained research assistants administered the Preschool Language Scales-4 (Zimmerman, Steiner \& Pond, 2002), a standardized measure of expressive and receptive language that has been shown to be appropriate for use across racial and socioeconomic groups (Zimmerman, Steiner \& Pond, 2004). The Expressive Communication subscale assesses how well the child communicates with others, whereas the Auditory Comprehension subscale is a measure of receptive vocabulary because it focuses on what children know or understand but may not say. Expressive Communication items range from assessing vocal development and social communication to naming common objects and using specific prepositions, grammatical markers, and sentence structures. The Auditory Comprehension subscale focuses on skills that are important precursors for language development (including appropriate object play and attention to speakers), in addition to the child's comprehension of basic vocabulary, concepts, and grammatical markers.

\section{Analytical Procedures}

Path models to test the hypotheses were estimated using the Full Information Maximum Likelihood estimation in AMOS 18.0 (SPSS Inc, Chicago, IL, USA). Overall model fit was evaluated using several fit indices: the comparative fit index (CFI), for which values above . 90 indicate a good model fit (Bentler, 1990; Kline, 2005), the Root Mean Square Error of Approximation (RMSEA; Steiger, 1990), for which values below .05 indicate an excellent model fit and values of .05 to .09 indicate an adequate fit (Browne \& Cudeck, 1993), and the $\chi^{2} / d f$ ratio for which ratios of less than 2.5 or 3 reflect a good model fit (Kline, 2005). All analyses were conducted with Expressive Language and then repeated with Receptive Language. Analyses proceeded in two steps. First, hypothesized differences in patterns of associations for girls and boys were estimated using a multiple-group comparison method (Bollen, 1989). An unconstrained model that allowed the path estimates to vary among girls and boys was estimated. Next, a fully constrained model that constrained all parameter estimates for girls and boys to be equal was estimated. If the fully constrained model resulted in a statistically significant decrement of model fit $\left(\chi^{2}\right)$ in comparison to the unconstrained model, then the pattern of associations varied for boys and girls. Finally, individual paths were released one at a time, and significant change in the $\chi^{2}$ statistic was examined. A statistically significant change in $\chi^{2}$ indicates that the magnitude of the path coefficient is statistically significantly different for girls and boys.

All estimated models included parenting, language, and social competence assessed at each time point, and paths from one time point to the next within each domain. That is, the coefficients representing stability from 24 to 36 months in sensitive parenting, language, and social competence were estimated. To control for the influence of earlier parenting, 
observed 12-month sensitive parenting was included in the model as a predictor of each 24month variable. The model also included the cross-lagged paths representing the relationships from 24-month scores in each variable to 36-month scores in all other variables.

\section{RESULTS}

\section{Descriptive and Correlational Analyses}

Prior to evaluating hypotheses, we examined descriptive variables and bivariate correlations among key constructs. As shown in Table 1, descriptive statistics were calculated separately for girls and boys. Possible mean differences among each of the key constructs for girls and boys were assessed by calculating $T$-tests. Results indicate mean-level differences in 36month language scores only. On average, girls scored significantly higher than boys on 36month expressive communication $(t(164)=2.86, p<.01))$ and receptive communication $(t(164)=2.77, p<.01))$. Turning next to correlational analyses, in general, there was a similar pattern of associations for girls and boys. There was considerable stability in parenting, social competence, and expressive and receptive language scores over time. Social competence at 24 and 36 months was positively correlated with 24-month expressive language for girls only. For boys and girls, sensitive parenting and receptive language were positively associated at 24 months.

\section{Path Model Analyses}

As described earlier, study hypotheses were evaluated by estimating path models in a series of four steps. The following section describes the results of each of these analyses. First, as seen in Figure 1, a model representing within domain stability and cross-lagged paths from one domain at a previous time point to the other domain at the next time point was estimated. The disturbance terms of each domain were allowed to covary. That is, the disturbance terms for 24- and 36-month sensitive parenting covaried, as did the disturbance terms for 24- and 36-month expressive/receptive language, and 24- and 36-month social competence. The model was first computed with Expressive Communication as the measured language variable and then re-computed with Receptive Communication. Hypothesized differences for girls and boys were tested using the multiple-group comparison method.

\section{Expressive Communication path model}

The fully unconstrained two group path model including Expressive Communication in which all path models were allowed to vary for boys and girls provided an adequate fit to the data, $\chi^{2}(14)=22.69, p<.05, \chi^{2} / d f=1.62, C F I=0.93, R M S E A=0.07$. Next, a fully constrained model that placed equality constraints on all parameters for boys and girls was estimated to examine the extent to which the patterns of associations varied by child sex. However, constraining all path coefficients to be equal for boys and girls failed to produce a statistically significant decrement in model fit, $\Delta \chi^{2}(10)=10.16, p=.43$. Therefore, the pattern of associations does not vary for girls and boys. 
Next, a model in which boys and girls were included in one group was estimated to evaluate the hypothesized associations. This model fit the data well, $\chi^{2}(3)=4.75, p=.19, \chi^{2} / d f=$ $1.58, C F I=0.99, R M S E A=0.06$. As shown in Figure 1, we then estimated a path model that trimmed four cross-lag paths that were not statistically significant. This model continued to provide an adequate fit to the data, $\chi^{2}(7)=12.17, p=.09, \chi^{2} / d f=1.71, C F I=0.98, R M S E A$ $=0.06$. The path coefficients indicate considerable stability across time in parenting and social competence. However, the beta coefficient estimating the relationship between 24and 36-month expressive communication failed to reach statistical significance. This indicates change in expressive communication across time, not only in the mean level, as noted in Table 2, but in the rank order within the sample. Further, more sensitive parenting at 24 months was linked to increases in expressive language at 36 months. At the same time, better social competence at 24 months predicted increases in sensitive parenting at 36 months, net the influence of sensitive parenting at 24 months on sensitive parenting at 36 months.

\section{Receptive Communication path models}

Identical procedures were followed to evaluate the hypothesized associations with receptive language. The fully unconstrained model including receptive language that allowed all paths to vary for boys and girls provided an adequate fit to the data, $\chi^{2}(14)=31.14, p=.01, \chi^{2} / d f$ $=2.22, C F I=0.95, R M S E A=0.09$. This model was re-estimated by constraining all paths to be equal for boys and girls. The fully constrained model resulted in a statistically significant decrement in model fit, $\chi^{2}(10)=19.39, p=.04$. Therefore, the pattern of associations varies for girls and boys. The model for girls that does not include the non-significant cross-lag paths is shown in Figure 2, and the model for boys is shown in Figure 3. Consistent with the findings reported earlier, for boys and girls, there is evidence of considerable stability in parenting and social competence across time points. Moreover, similar to the findings for expressive communication, more sensitive parenting behaviours at 24 months are associated with higher receptive communication scores at 36 months. To identify the specific sex differences, paths that varied for girls and boys were evaluated by constraining those paths to be equal in both groups and then comparing the fit of the models with and without the equality constraint by using the chi-square statistic. A statistically significant decrement in model fit indicates that the specific path was statistically significantly different for girls and boys. Turning first to stability across time in language development, the path from 24-month receptive language to 36-month receptive language emerged as statistically significant for girls only $(\beta=.88, p<.001$ for girls; $\beta=.14, p=.15$ for boys). When this path was constrained to be equal for boys and girls, there was a corresponding decrement of model fit, $\Delta \chi^{2}(1)=12.14, p=.04$. Next, the findings indicate that among girls, only mother-reported social competence at 24 months is associated with more observed sensitive parenting at 36 months ( $\beta=.20, p=.03$ for girls; $\beta=.05, p=.44$ for boys). However, constraining that path to be equal for girls and boys did not decrease the model fit, $\Delta \chi^{2}(1)=1.45, p=.23$, and thus, we cannot conclude that the link between social competence and sensitive parenting over time is significantly greater for girls than for boys. Finally, the results show that when boys have better receptive communication at 24 months, their mothers engage in more sensitive parenting at 36 months, controlling for the influence of earlier parenting and social competence on 36-month parenting ( $\beta=-.09, p=.33$ for girls; $\beta=.28, p=.002$ for boys). 
This finding holds when the paths are constrained to be equal for boys and girls by resulting in a statistically significant decrement in model fit, $\Delta \chi^{2}(1)=7.30, p=.01$. Thus, 24-month receptive language skills are associated with the 36-month parenting of mothers of boys only.

\section{DISCUSSION}

This study employed observational and mother-reported data to examine interrelations among sensitive parenting, expressive and receptive language development, and social competence from 24 to 36 months. No evidence was found for cross-domain interactions over time between social competence and language development by using stringent tests of bidirectional (i.e. cross-lag) relationships. However, there is support for a transactional model of parent-child relationships because the findings indicate that sensitive parenting predicts language development and children's social competence and language skills predict mothers' sensitive parenting behaviours. Moreover, the processes linking sensitive parenting, language development, and social competence vary for girls and boys.

\section{Links Between Language Development and Social Competence}

The findings from the present study are consistent with previous research, suggesting relative stability in both social competence (e.g. Hay et al., 1999) and language development (e.g. Bornstein et al., 2004) during early childhood. However, the present results indicate that these patterns of within domain developmental stability vary by child sex. Receptive and expressive language skills among girls are more integrated at 24 months and more stable from 24 to 36 months in comparison to boys. For boys, only expressive language is stable from 24 to 36 months. At the mean level, a female advantage in receptive and expressive communication does not emerge until the 36-month assessment. This sex difference could indicate that the building blocks facilitating more advanced expressive and receptive language development among girls by 36 months were already in place by 24 months such that there was less individual change over time in language development. On the other hand, both boys and girls demonstrated across-time stability and similar mean levels of social competence.

The results fail to support hypotheses regarding cross-domain interactions between language skills and social competence for boys or girls, as there was no evidence of unique prediction of 36-month social competence from 24-month expressive or receptive language skills, or vice versa. Although gains in social competence and language skills are significant developmental tasks during the third year of life, the present findings suggest that development in the social and cognitive domains is somewhat separate. Despite the fact that both language skills and social skills are often expressed within the same context, the influences of one domain of development on the other domain cannot be isolated in the present study.

\section{Bidirectional Associations Among Parenting, Language, and Social Competence}

We found mixed support for expectations regarding transactional relationships between mothers' sensitive parenting and children's expressive and receptive language development 
and social competence. Consistent with existing research, the present findings indicate that mothers' sensitive parenting at 12 months was positively associated with both kinds of language skills and social competence at 24 months. Although bivariate correlations suggest that mothers' sensitive parenting and children's social competence at 24 and 36 months were positively related within time, there was no evidence that mothers' sensitive parenting predicted increases in social competence from 24 to 36 months. However, above and beyond the influence of 24-month expressive and receptive language scores, mothers' sensitive parenting predicted increases in both kinds of language development for girls and boys. These findings add to the work of Pungello et al. (2009) with a subsample of the present study by demonstrating a positive association between sensitive parenting and rate of growth in language by explicitly considering the bidirectional relationship between sensitive parenting and children's language skills, and the role of child sex as a moderator of parenting and language development.

A primary goal of the present study was to apply a transactional model to identify the extent to which sensitive parenting behaviours shape and are shaped by children's expressive and receptive language skills and social competence. Mixed evidence of bidirectional associations between mothers' observed parenting behaviours and mother-rated social competence of girls and boys was found. That is, 12-month sensitive parenting was positively associated with children's 24-month social competence, and 24-month social competence predicted increases in 36-month sensitive parenting. When children displayed higher levels of social competence, including following directions and cooperating, their mothers may have responded with warmer, more sensitive behaviours. Given the stability of social competence across the third year of life, earlier positive influences of mothers' sensitive parenting on social competence may resonate across toddlerhood by contributing to later increases in sensitive parenting. This finding supports the utility of transactional models of child development to understand escalations of positive behaviours over time as a complement to the body of research demonstrating reciprocities in negative parent-child behaviours over time (e.g. Patterson, 2002; Gross et al., 2008).

Consistent with previous findings (e.g. Baillargeon et al., 2007), the present study reports no mean differences in social competence among girls and boys at this age and no evidence that child sex moderates the bidirectional associations among sensitive parenting and social competence. However, also in line with existing work, we find evidence of child sex differences in patterns describing language development (e.g. Bornstein et al., 2004). In support of a transactional model of sensitive parenting and children's early language skills, better receptive communication skills at 24 months predicted increases in mothers' sensitive parenting from 24 to 36 months for boys only. Interestingly, past research indicates that the association between behaviour problems and receptive vocabulary delays is stronger than that between behaviour problems and expressive language delays (Beitchman et al., 1996; Ross \& Weinberg, 2006). Boys are at higher risks for the development of behaviour problems than girls by preschool, and transactions between mothers' positive parenting and boys' receptive communication skills may be an important risk factor. Children with greater receptive language skills can better comprehend mothers' comments and directions, and thus, they may respond appropriately, encouraging positive behaviours from mothers. The 
behaviour during parent-child interactions is likely different for boys with lower versus higher receptive communication skills, and mothers are in fact responding to those behaviours. For example, when a mother asks a child to follow a command, and the child does so immediately, then the mother is likely to respond with praise that in turn may cause the child to direct positive attention towards the mother. On the other hand, children with poorer receptive communication skills may be less compliant to mothers' requests because they do not understand those requests, and then mothers may need to use more forceful, directive strategies, and/or they may become irritated by and dismissive of their sons' noncompliance. In fact, boys may be less compliant than girls during this developmental period (Smith et al., 2004). Perhaps boys with more advanced receptive communication skills behave more like girls, in that they may be more compliant and in general more responsive to mothers, and in turn their mothers are more sensitive towards them (Bornstein et al., 2007; Leaper, 2002). Interestingly, this transactional developmental pattern does not apply to expressive language, suggesting that at this age, mothers may respond more to what children do than what they say. Perhaps some of the items assessing receptive language skills are also indicative of compliance. For example, children are asked to follow specific commands (e.g. 'Put the block in the box.'). Following the command correctly is evidence that they understood the command and were cooperative.

The present findings cannot distinguish whether there is a sex-based difference in the processes linking parenting with language development or whether there is a sex-based difference in the timing of these linkages. We may see effects of boys' receptive language on mothers' parenting because there is more variability in boys' language scores over this developmental period. Similar processes may have been in effect earlier in development for girls' receptive language skills and for expressive language development of both boys and girls. Future research is required to disentangle the direction of effects starting in the first year of life and continuing across early childhood to pinpoint the extent to which language development and social competence are reciprocally related to sensitive parenting practices.

\section{Study Strengths and Limitations}

The present study has a number of strengths. First, this study uses multi-method assessment, including observations of mother's parenting, mother-reported social competence, and standardized language assessment. In addition, this study demonstrates relationships between language development and social competence among a typically developing community sample, thus offering a complementary perspective to research regarding connections between social competence and language development among children with language impairments or behavioural disorders (e.g. Rescorla et al., 2007). Moreover, the findings support transactional models of socialization that are influenced by boys' receptive language and girls' and boys' social competence. Specifically, bidirectional associations between social competence and sensitive parenting indicate that early childhood can be marked by escalating positive cycles.

Despite these strengths, the study is not without limitations. First, the sample is a relatively small community sample, and thus, the findings may not generalize to larger, more diverse populations. Second, only mothers' parenting is considered, and the transactional patterns 
may vary for fathers' parenting. Third, we rely on mothers' reports of children's social competence. Finally, parenting, language, and social competence are only measured at 24 and 36 months. Given rapid developmental changes that occur during this period and the related need for parenting adjustments, a study including multiple time points during the third year may more accurately capture the transactional nature of child development across this period.

\section{CONCLUSIONS}

This study highlights the utility of examining the interrelations among parenting behaviours, language, and social competence during early childhood. We find no evidence of crossdomain interactions between language and social competence. However, in support of transactional models of parent-child relationships, we find that mothers' sensitive parenting is reciprocally linked to boys' and girls' social competence and to boys' receptive language skills. This study also underscores the role that children's positive behaviours may play in the enactment of mothers' positive parenting behaviours, indicating that during early childhood, parent-child relationships may be characterized by positive cycles of interaction. Therefore, simultaneously focusing on bolstering children's and mothers' development in positive domains may be an efficient and effective strategy for prevention and intervention programmes.

\section{Acknowledgments}

This study was supported by the North Carolina Child Development Research Collaborative, which is funded by the National Science Foundation through Children's Research Initiative Grant \#BCS-0126475. The authors thank the families who participated in the Durham Child Health and Development Study. The authors also thank the research assistants for their valuable help with collecting and coding the data.

\section{References}

Ayoub C, Vallotton CD, Mastergeorge AM. Developmental pathways to integrated social skills: The roles of parenting and early intervention. Child Development. 2011; 82:583-600.10.1111/j. 1467-8624.2010.01549.x [PubMed: 21410921]

Baillargeon RH, Normand CL, Séguin JR, Zoccolillo M, Japel C, Pérusse D, et al. The evolution of problem and social competence behaviors during toddlerhood: A prospective population-based cohort survey. Infant Mental Health Journal. 2007; 28:12-38.10.1002/imhj.20120

Beitchman JH, Wilson B, Brownlie EB, Walters H, Lancee W. Long-term consistency in speech/ language profiles: I. Developmental and academic outcomes. Journal of the American Academy of Child and Adolescent Psychiatry. 1996; 35:804-814. [PubMed: 8682762]

Bentler PM. Comparative fit indexes in structural models. Psychological Bulletin. 1990; 107:238-246. [PubMed: 2320703]

Bollen, KA. Structural equations with latent variables. New York: Wiley; 1989.

Bornstein, MH. Toward a model of culture-parent-child transactions. In: Sameroff, A., editor. The transactional model of development: How children and contexts shape each other. Washington, DC: American Psychological Association; 2009. p. 139-161.

Bornstein MH, Hahn C, Haynes OM. Specific and general language performance across early childhood: Stability and gender considerations. First Language. 2004; 24:267304.10.1177/0142723704045681

Bornstein MH, Hendricks C, Haynes O, Painter KM. Maternal sensitivity and child sensitiveness: Associations with social context, maternal characteristics, and child characteristics in a multivariate analysis. Infancy. 2007; 12:189-223.10.1111/j.1532-7078.2007.tb00240.x 
Bouchard C, Cloutier R, Gravel F, Sutton A. The role of language skills in perceived prosociality in kindergarten boys and girls. The European Journal of Developmental Psychology. 2008; 5:338-357.

Browne, MW.; Cudeck, R. Alternative ways of assessing model fit. In: Bollen, KA.; Long, JS., editors. Testing structural equation models. Newbury Park, CA: Sage; 1993. p. 136-162.

Calkins SD. Does aversive behavior during toddlerhood matter? The effects of difficult temperament on maternal perceptions and behavior. Infant Mental Health Journal. 2002; 23:381-402.

Cox, MJ. Qualitative ratings for parent-child interaction at 24-36 months of age. Department of Psychology; University of North Carolina at Chapel Hill: 1997. Unpublished manuscript

Cox, M.; Crnic, K. Qualitative ratings for parent-child interaction at 3-12 months of age. Department of Psychology; University of North Carolina at Chapel Hill: 2002. Unpublished manuscript

Dionne G, Tremblay R, Boivin M, Laplante D, Perusse D. Physical aggression and expressive vocabulary in 19-month-old twins. Developmental Psychology. 2003; 39:261-273. [PubMed: 12661885]

Dunsmore JC, Noguchi RJP, Garner PW, Casey EC, Bhullar N. Gender-specific linkages of affective social competence with peer relations in preschool children. Early Education and Development. 2008; 19:211-237.

Fenson L, Dale PS, Reznick JS, Bates L, Thal DJ, Pethick SJ, et al. Variability in early communicative development. Monographs of the Society for Research in Child Development. 1994; 59:1-173. [PubMed: 7845413]

Fischer, KW.; Bidell, TR. Dynamic development in action and thought. In: Damon, W.; Lerner, RM., editors. Handbook of child psychology: Theoretical models of human development. 6. Vol. 1. New York: Wiley; 2006. p. 313-399.

Gallagher TM. Interrelationships among children's language, behavior, and emotional problems. Topics in Language Disorders. 1999; 19:1-15.

Galsworthy MJ, Dionne G, Dale PS, Plomin R. Sex differences in early verbal and non-verbal cognitive development. Developmental Science. 2000:206-215.

Gleason, J.; Ely, R. Gender differences in language development. In: McGillicuddy-De Lisi, A.; De Lisi, R., editors. Biology society and behavior: The development of sex differences in cognition. Westport, CT: Albex; 2002. p. 127-154.

Gross HE, Shaw DS, Moilanen KL. Reciprocal associations between boys' externalizing problems and mothers' depressive symptoms. Journal of Abnormal Child Psychology. 2008; 36:693709.10.1007/s10802-008-9224-x [PubMed: 18288602]

Hay DF, Castle J, Davies L, Demetriou H. Prosocial action in very early childhood. Journal of Child Psychology and Psychiatry. 1999; 40:905-916. [PubMed: 10509885]

Hogan AE, Scott KG, Bauer CR. The Adaptive Social Behavior Inventory (ASBI): A new assessment of social competence in high risk three year olds. Journal of Psychoeducational Assessment. 1992; 10:230-239.

Horwitz SM, Irwin JR, Briggs-Gowan MJ, Bosson Heenan J, Mendoza J, Carter AS. Language delay in a community cohort of young children. Journal of the American Academy of Child and Adolescent Psychiatry. 2003; 42:932-940. [PubMed: 12874495]

Howes C, Phillipsen L. Continuity in children's relations with peers. Social Development. 1998; 7:340-349.10.1111/1467-9507.00071

Kaiser AP, Hancock TB, Cai X, Foster EM. Parent-reported behavioral problems and language delays in boys and girls enrolled in Head Start classrooms. Behavioral Disorders. 2000; 26:26-41.

Kline, RB. Principles and practice of structural equation modeling. 2. New York: Guilford Press; 2005.

Kochanska G, Coy KC, Murray KT. The development of self-regulation in the first four years of life. Child Development. 2001; 72:1091-1111. [PubMed: 11480936]

Landry S, Smith KE, Swank PR, Miller-Loncar CL. Early maternal and child influences on children's later independent cognitive and social functioning. Child Development. 2000; 71:358-375. [PubMed: 10834470]

Leaper, C. Parenting boys and girls. In: Bornstein, MH., editor. Handbook of parenting: Children and parenting. Vol. 1. Hillsdale, NJ: Erlbaum; 2002. p. 189-225. 
Leaper C, Anderson KJ, Sanders P. Moderators of gender effects on parents' talk to their children: A meta-analysis. Developmental Psychology. 1998; 34:3-27.10.1037/0012-1649.34.1.3 [PubMed: 9471001]

Lengua LJ, Honorado E, Bush NR. Contextual risk and parenting as predictors of effortful control and social competence in preschool children. Journal of Applied Developmental Psychology. 2007; 28:40-55. [PubMed: 21687825]

Lerner, RM. Developmental science, developmental systems, and contemporary theories of human development. In: Damon, W.; Lerner, RM., editors. Handbook of child psychology: Theoretical models of human development. 6. Vol. 1. Hoboken, NJ: Wiley; 2006. p. 1-17.

Longoria AQ, Page MC, Hubbs-Tait L, Kennison SM. Relationship between kindergarten children's language ability and social competence. Early Child Development and Care. 2009; 179:919-929.

McCabe PC, Meller PJ. The relationship between language and social competence: How language impairment affects social growth. Psychology in the Schools. 2004; 41:313-321.

NICHD Early Child Care Research Network. Child care and mother-child interaction in the first three years of life. Developmental Psychology. 1999; 35:1399-1413. [PubMed: 10563730]

Patterson, GR. The early developmental of coercive family process. In: Reid, JB.; Patterson, GR.; Snyder, J., editors. Antisocial behavior in children and adolescents: Developmental theories and models for intervention. Washington, DC: American Psychological Association; 2002. p. 25-44.

Pungello EP, Iruka IU, Dotterer AM, Mills-Koonce WR, Reznick JS. The effects of socioeconomic status, race, and parenting on language development in early childhood. Developmental Psychology. 2009; 45:544-557. [PubMed: 19271838]

Rescorla L, Ross GS, McClure S. Language delay and behavioral/emotional problems in toddlers: Findings from two developmental clinics. Journal of Speech, Language, and Hearing Research. 2007; 50:1063-1078.10.1044/1092-4388(2007/074)

Ross G, Weinberg S. Is there a relationship between language delays and behavior and socialization problems in toddlers? Journal of Early Childhood and Infant Psychology. 2006:101-116.

Rowe ML. Pointing and talk by low-income mothers and their 14-month-old children. First Language. 2000; 20:305-330.10.1177/014272370002006005

Rutter M, Caspi A, Moffitt TE. Using sex differences in psychopathology to study causal mechanisms: Unifying issues and research strategies. Journal of Child Psychology and Psychiatry. 2003; 44:1092-1115. [PubMed: 14626453]

Sameroff, AJ., editor. The transactional model of development: How children and contexts shape each other. Washington, DC: American Psychological Association; 2009.

Smith CL, Calkins SD, Keane SP, Anastopoulos AD, Shelton TL. Predicting stability and change in toddler behavior problems: Contributions of maternal behavior and child gender. Developmental Psychology. 2004; 40:29-42.10.1037/0012-1649.40.1.29 [PubMed: 14700462]

Spinrad TL, Eisenberg N, Gaertner B, Popp T, Smith CL, Kupfer A, et al. Relations of maternal socialization and toddlers' effortful control to children's adjustment and social competence. Developmental Psychology. 2007; 43:1170-1186. [PubMed: 17723043]

Steiger JH. Structural model evaluation and modification: An internal estimation approach. Multivariate Behavioral Research. 1990; 25:173-180.

Stowe RM, Arnold DH, Ortiz C. Gender differences in the relationship of language development to disruptive behavior and peer relationships in preschoolers. Journal of Applied Developmental Psychology. 1999; 20:521-536.

Tamis-LeMonda CS, Bornstein MH, Baumwell L. Maternal sensitiveness and children's achievement of language milestones. Child Development. 2001; 72:748-767. [PubMed: 11405580]

Thelen, E.; Smith, LB. Dynamic systems theories. In: Damon, W.; Lerner, RM., editors. Handbook of child psychology: Theoretical models of human development. 6. Vol. 1. Hoboken, NJ: Wiley; 2006. p. 258-312.

Zimmerman, IL.; Steiner, VG.; Pond, RE. The Preschool Language Scale: Fourth edition, examiner's manual. San Antonio, TX: The Psychological Corporation; 2002.

Zimmerman, IL.; Steiner, VG.; Pond, RE. The Preschool Language Scale. Fourth Edition. San Antonio, TX: The Psychological Corporation; 2004. 


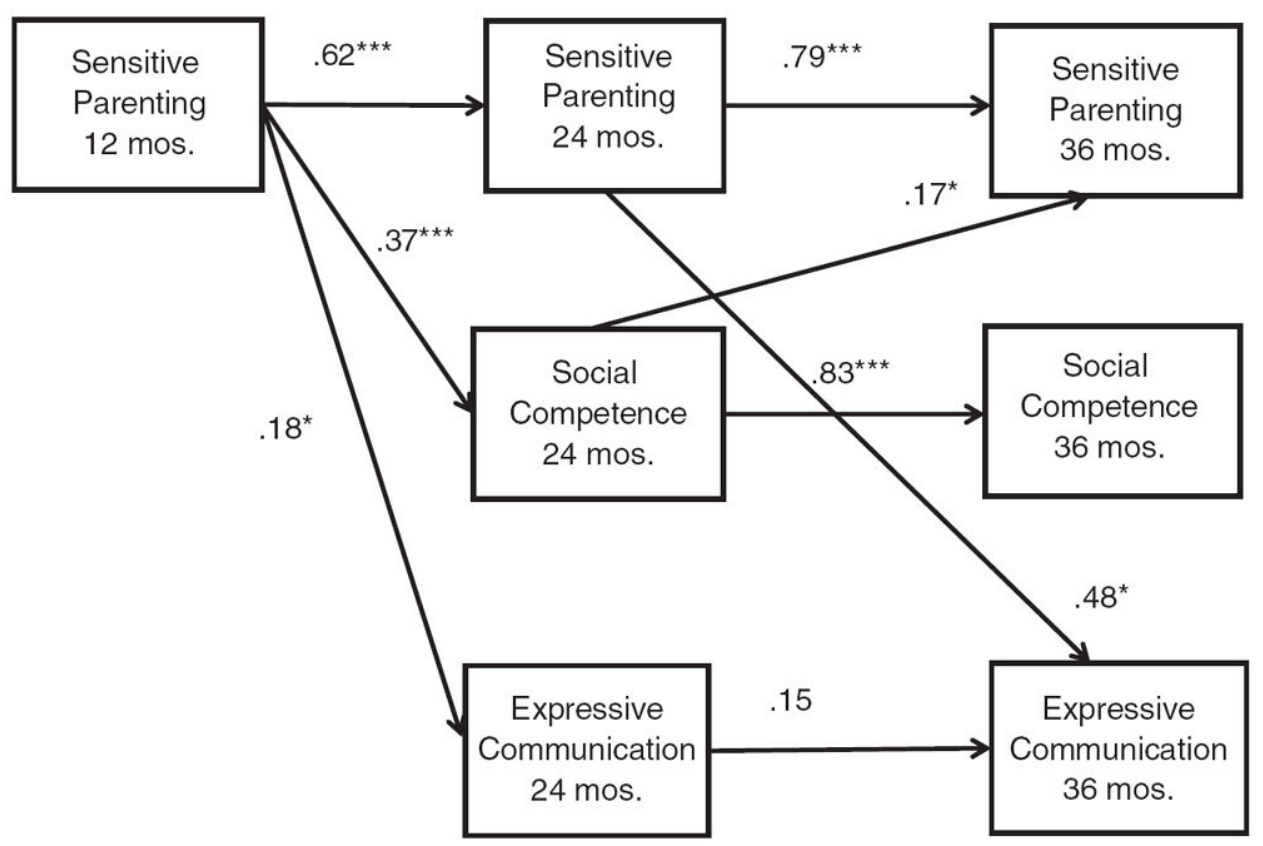

Figure 1.

Standardized regression coefficients for path model including expressive communication for boys and girls with non-significant cross-lag paths trimmed.

Note: $* p<.05 ; * * p<.01, * * * p<.001$

$\chi^{2}(3)=12.17, p=.10, \chi^{2} / d f=1.71, \mathrm{CFI}=0.98, \mathrm{RMSEA}=0.06$ 


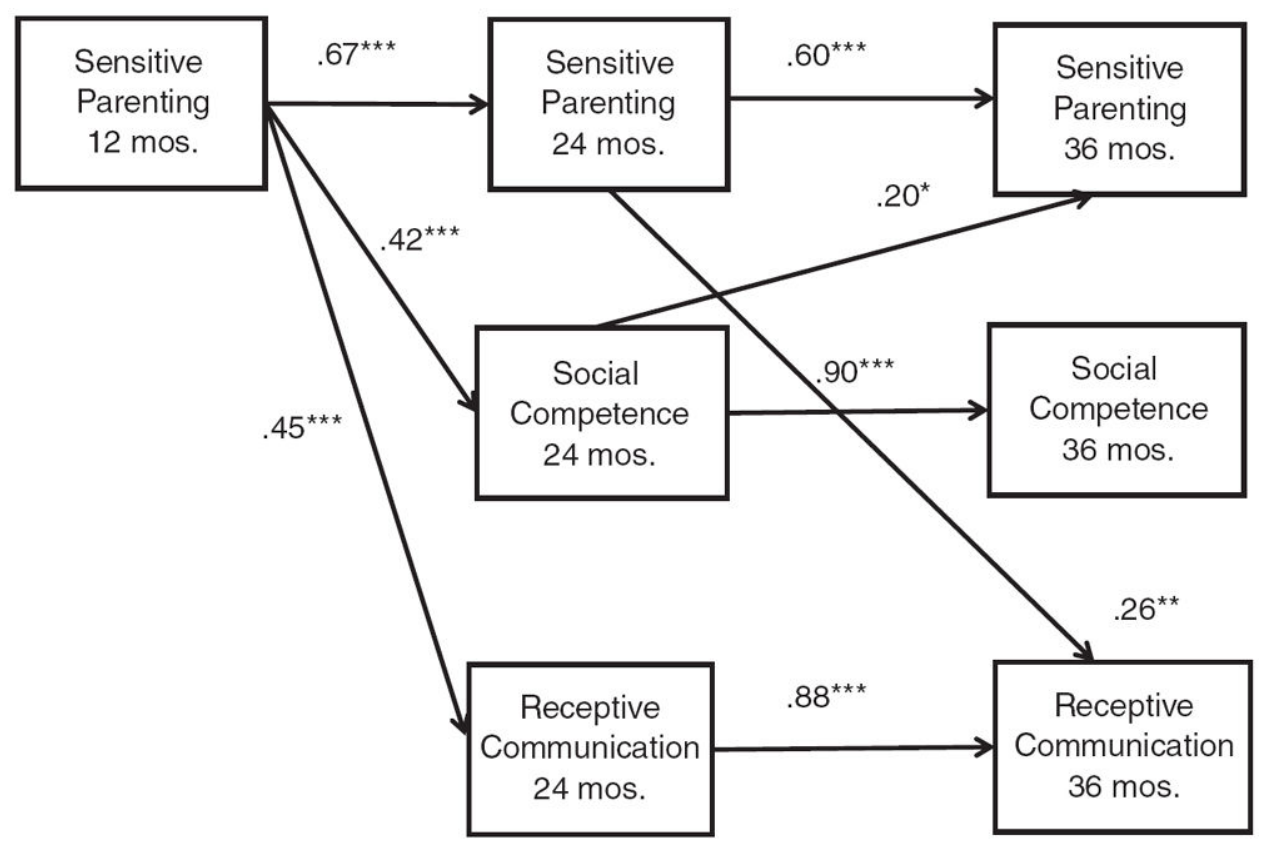

Figure 2.

Standardized regression coefficients for path model including receptive communication for girls with non-significant cross-lag paths trimmed.

Note: $* p<.05 ; * * p<.01, * * * p<.001$

$\chi^{2}(6)=11.02, p=.07, \chi^{2} / d f=1.83, \mathrm{CFI}=0.94, \mathrm{RMSEA}=0.08$ 


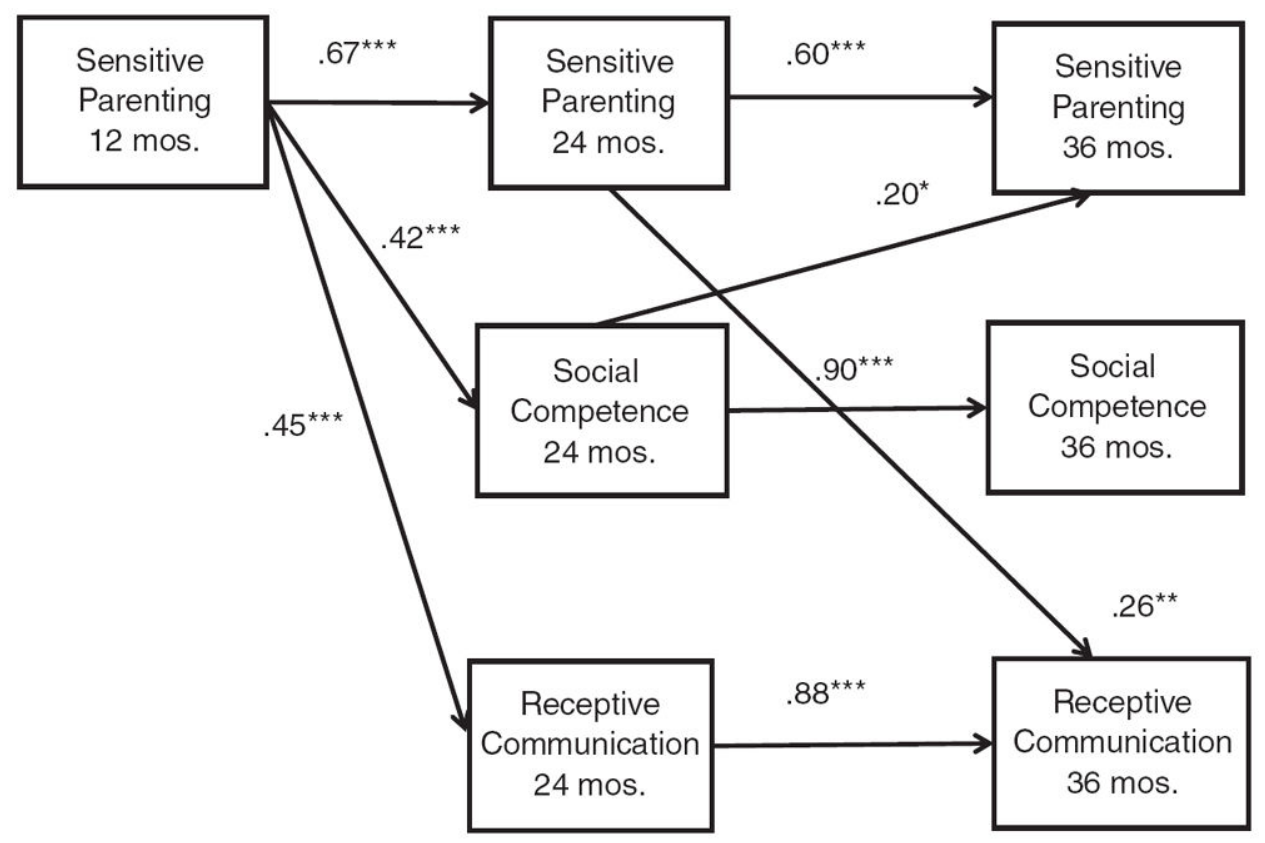

Figure 3.

Standardized regression coefficients for path model including receptive communication for boys with non-significant cross-lag paths trimmed.

Note: $* p<.05 ; * * p<.01, * * * p<.001$

$\chi^{2}(7)=10.24, p=.18, \chi^{2} / d f=1.46, \mathrm{CFI}=0.98, \mathrm{RMSEA}=0.07$ 
